\title{
Peranan Audit Sistem Informasi Pada Perusahaan
}

\author{
Ranita Sari \\ 175100004 \\ Fakultas Komputer \\ ranitasari.students@umitra.ac.id
}

\begin{abstract}
Dalam lingkup perusahaan, audit sistem informasi dapat ditujukan untuk mengamankan aset-aset perusahaan, menjaga integritas data, menjaga efektivitas sistem, dan mencapai efisiensi sumber daya. Mengamankan aset yang berhubungan dengan instalasi sistem informasi mencakup: perangkat keras (hardware), perangkat lunak (software), manusia (people), file data, dokumentasi sistem, dan peralatan pendukung lainnya. Integritas data merupakan data yang memenuhi aspek kelengkapan, baik dan dipercaya, kemurnian, dan ketelitian. Data yang berintegritas merupakan langkah awal yang penting untuk mendapatkan hasil yang akurat. Sistem informasi dikatakan efektif hanya jika sistem tersebut dapat mencapai tujuannya. Sistem informasi harus memberikan output berupa informasi yang diperlukan oleh pemegang keputusan. Penilaian efektivitas mengukur apakah kinerja sistem layak dipertahankan, harus ditingkatkan atau perlu dimodifikasi, atau sistem sudah usang, sehingga harus ditinggalkan dan dicari penggantinya. Efisiensi sistem informasi juga harus diukur untuk menghasilkan output yang diharapkan dengan sumber daya yang seminimal mungkin.
\end{abstract}

Kata Kunci : Mengamankan aset perusahaan. 


\section{A. PENDAHULUAN}

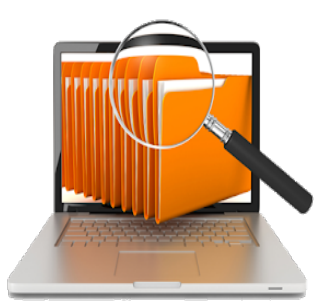

Audit sistem informasi atau Information System Audit disebut juga EDP Audit (Electronc Data Processing Audit) atau computer audit merupakan suatu proses dikumpulkannya data dan dievakuasinya bukti untuk menetapkan apakah suatu sistem aplikasi komputerisasi sudah diterapkan dan menerapkan sistem pengendalian internal yang sudah sepadan, seluruh aktiva dilindungi dengan baik atau disalahgunakan dan juga terjamin integritas data, keandalan dan juga efektifitas dan efisiensi penyelenggaraan informasi berbasis komputer. Audit sistem informasi merupakan gabungan dari berbagai

Faktor-faktor yang mendorong pentingnya kontrol dan audit sistem informasi adalah :

- Mendeteksi agar komputer tidak dikelola secara kurang terarah.

- Mendeteksi resiko kehilangan data.

- Mendeteksi resiko pengambilan keputusan yang salah akibat informasi hasil proses sistem komputerisasi salah/lambat/tidak lengkap.

- Menjaga aset perusahaan macam ilmu, antara lain traditional audit, manajemen sistem informasi, sistem informasi akuntansi, ilmu komputer, dan behavioral science. Menurut Ron Weber (2010) audit sistem informasi adalah proses pengumpulan dan penilaian bukti-bukti untuk menentukan apakah sistem komputer dapat mengamankan aset, memelihara integritas data, dapat mendorong pencapaian tujuan organisasi secara efektif dan menggunakan sumberdaya secara efisien. Beberapa aspek yang diperiksa pada audit sistem informasi seperti efektifitas, efisiensi, availability system, reliability, confidentiality, dan integrity, aspek security, audit atas proses, modifikasi program, audit atas sumber data, dan data file.

karena nilai hardware, software dan personil yang lazimnya tinggi.

- Mendeteksi resiko error komputer.

- Mendeteksi resiko penyalahgunaan komputer (fraud).

- Menjaga kerahasiaan

- Meningkatkan pengendalian evolusi penggunaan komputer

Tujuan audit sistem informasi menurut Ron Weber secara garis besar yaitu: 
- Pengamanan Aset. Aset informasi suatu perusahaan seperti perangkat keras (hardware), perangkat lunak (software), sumber daya manusia, file data harus dijaga oleh suatu sistem pengendalian internal yang baik agar tidak terjadi penyalahgunaan aset perusahaan. Dengan demikian sistem pengamanan aset merupakan suatu hal yang sangat penting yang harus dipenuhi oleh perusahaan.

- Menjaga Integritas Data. Integritas data (data integrity)

\section{B.PEMBAHASAN / STUDI KASUS}

Audit sistem informasi awalnya dikenal dengan nama audit EDP (Electronic Data Processing). Audit EDP muncul ketika para akuntan public tersertifikasi menyadari pentingnya adanya audit untuk sistem informasi perusahaan. Lembaga audit EDP pertama kali muncul pada tahun 1968. Tuntunan, prosedur, dan standar yang dibuat oleh lembaga tersebut saat ini dikenal sebagai Control Objectives for Information and Related Technology (COBIT).

\section{TUJUAN AUDIT SISTEM INFORMASI}

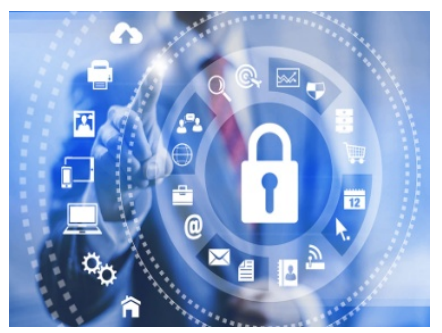

a) Pengamanan aset. Aset informasi suatu perusahaan seperti perangkat keras (hardware), perangkat lunak (software), sumber daya manusia, dan data harus dijaga dengan sistem pengendalian intern yang baik agar tidak ada penyalahgunaan aset perusahaan.

b) Efektifitas sistem informasi perusahaan memiliki peranan penting dalam proses pengmbilan keputusan. Suatu sistem informasi dapat dikatakan efektif bila sistem informasi tersebut sudah dirancang dengan benar (doing the right thing), telah sesuai dengan kebutuhan user. Informasi yang dibutuhkan oleh para manajer dapat dipenuhi dengan baik.

c) Efisiensi sistem menjadi sangat penting ketika sumber daya kapasitasnya terbatas. Jika cara kerja dari sistem aplikasi komputer menurun maka pihak manajemen harus mengevaluasi apakah efisiensi sistem masih memadai atau harus menambah sumber daya, karena suatu

sistem dapat dikatakan efisien jika sistem informasi dapat memnuhi kebutuhan user dengan sumber daya informasi yang minimal. Cara kerja sistem benar (doing thing right).

d) Ketersediaan (Availability) Berhubungan dengan ketersediaan dukungan/layanan

teknologi informasi (TI). TI hendaknya dapat mendukung secara kontinyu terhadap proses bisnis kegiatan perusahaan. Makin sering terjadi gangguan (system down) maka berarti tingkat ketersediaan sistem rendah.

e) Kerahasiaaan (Confidentiality) Fokusnya ialah pada proteksi terhadap informasi dan supaya terlindungi dari akses dari pihak yang idak berwenang.

f) Kehandalan (Realibility) Berhubungan dengan kesesuaian dan kekuratan bagi manajemen dalam pengolahan organisasi, pelaporan dan pertanggungjawaban.

g) Menjaga integritas data adalah salah 
satu konsep dasar sistem informasi.

Data memiliki atribut-atribut seperti

kelengkapan kebenaran dan

keakuratan.

\section{Tujuan audit sistem informasi secara teknis yaitu:}

a) Evaluasi atas kesesuaian antara rencana strategis dengan rencana tahunan organisasi,rencana tahunan dan rencana proyek.

b) Evaluasi atas kelayakan struktur organisasi yaitu termasuk pemisahan fungsi dan kelayakan pelimpahan wewennang dan otoritas.

c) Evaluasi atas pengelolahan personil yaitu termasuk perencanaan kebutuhan, rekrutmen dan seleksi, pelatihan dan pendidikan, promosi,mutasi, serta terminasi personil.

d) Evaluasi atas pengembangan yaitu termasuk analisis kebutuhan, perancangan, pengembangan, pengujian, implementasi,

\section{C.ID SECURITY}

QWTD4452377-ASP-5244166

\section{D.KESIMPULAN}

Audit Sistem Informasi Merupakan suatu proses

pengumpulan\&pengevaluasian buktibukti yang dilakukan oleh pihak yang independen\&kompeten untuk mengetahui apakah suatu sistem informasi dan sumber daya terkait, secara memadai telah dapat digunakan untuk:melindungi aset,menjaga integritas\&ketersediaan sistem\&data,menyediakan informasi yang relevan\&handal,mencapai tujuan organisasi dengan efektif,menggunakan sumber daya dengan efisien,System informasi menyiratkan penggunaan teknologi komputer dalam suatu organisasi untuk menyediakan informasi bagi pengguna.Sistem informasi berbasiskomputer merupakansatu rangkaian perangkat lunak\&perangkat lunak yang dirancang untuk mentransformasi data menjadi informasi yang

berguna,secara memadai dapat digunakan untuk:

*Melindungi aset

* Menjaga integritas dan ketersediaan sistem dan data

*Menyediakan informasi yang relevan dan handal

* Mencapai tujuan organisasi dengan efektif

* Menggunakan sumber daya dengan efisien,

\section{E.DISKUSI}

Saya bersama teman saya bernama DIAN mendiskusikan tentang contoh ini dengan sangat baik Hasil diskusi dari materi ini adalah menerangkan tentang lingkup perusahaan, audit sistem informasi dapat ditujukan untuk mengamankan aset-aset perusahaan, menjaga integritas data, menjaga efektivitas sistem, dan mencapai efisiensi sumber daya. Mengamankan aset yang berhubungan dengan instalasi sistem informasi mencakup: perangkat keras (hardware), perangkat lunak (software), manusia (people), file data, dokumentasi sistem, dan peralatan 
pendukung lainnya

\section{F.REFERENCE}

[1] O. M. Febriani and A. S. Putra, "Sistem Informasi Monitoring Inventori Barang Pada Balai Riset Standardisasi Industri Bandar Lampung," J. Inform., vol. 13, no. 1, pp. 90-98, 2014.

[2] A. S. Putra, "Paperplain: Execution Fundamental Create Application With Borland Delphi 7.0 University Of Mitra Indonesia," 2018.

[3] A. S. Putra, "2018 Artikel Struktur Data, Audit Dan Jaringan Komputer," 2018.
[4] A. S. Putra, "ALIAS MANAGER USED IN DATABASE DESKTOP STUDI CASE DB DEMOS."

[5] A. S. Putra, "COMPREHENSIVE SET OF PROFESSIONAL FOR DISTRIBUTE COMPUTING."

[6] A. S. Putra, "DATA ORIENTED RECOGNITION IN BORLAND DELPHI 7.0."

[7] A. S. Putra, "EMBARCADERO DELPHI XE 2 IN GPU-POWERED FIREMONKEY APPLICATION."

[8] A. S. Putra, "HAK ATAS KEKAYAAN INTELEKTUAL DALAM DUNIA TEKNOLOGY BERBASIS REVOLUSI INDUSTRI 4.0."

[9] A. S. Putra, "IMPLEMENTASI PERATURAN PERUNDANGAN UU. NO 31 TAHUN 2000 TENTANG DESAIN INDUSTRI BERBASIS INFORMATION TECHNOLOGY."

[10] A. S. Putra, "IMPLEMENTATION OF PARADOX DBASE."

[11] A. S. Putra, "IMPLEMENTATION of TRADE SECRET CASE STUDY SAMSUNG

[12] A. S. Putra, "IMPLEMENTATION PATENT FOR APPLICATION WEB BASED CASE STUDI WWW. PUBLIKLAMPUNG. COM."

[13] A. S. Putra, "IMPLEMENTATION SYSTEM FIRST TO INVENT IN DIGITALLY INDUSTRY."

[14] A. S. Putra, "MANUAL REPORT \& INTEGRATED DEVELOPMENT 
ENVIRONMENT BORLAND DELPHI 7.0."

[15] A. S. Putra, "PATENT AS RELEVAN SUPPORT RESEARCH."

[16] A. S. Putra, "PATENT FOR RESEARCH STUDY CASE OF APPLE. Inc."

[17] A. S. Putra, "PATENT PROTECTION FOR APPLICATION INVENT."

[18] A. S. Putra, "QUICK REPORT IN PROPERTY PROGRAMMING."

[19] A. S. Putra, "REVIEW CIRCUIT LAYOUT COMPONENT REQUIREMENT ON ASUS NOTEBOOK."

[20] A. S. Putra, "REVIEW TRADEMARK PATENT FOR INDUSTRIAL TECHNOLOGY BASED 4.0."

[21] A. S. Putra, "TOOLBAR COMPONENT PALLETTE IN OBJECT ORIENTED PROGRAMMING."

[22] A. S. Putra, "WORKING DIRECTORY SET FOR PARADOX 7."

[23] A. S. Putra, "ZQUERY CONNECTION IMPLEMENTED PROGRAMMING STUDI CASE PT. BANK BCA Tbk."

[24] A. S. Putra, D. R. Aryanti, and I. Hartati, "Metode SAW (Simple Additive Weighting) sebagai Sistem Pendukung Keputusan Guru Berprestasi (Studi Kasus: SMK Global Surya)," in Prosiding Seminar Nasional Darmajaya, 2018, vol. 1, no. 1, pp. 85-97.

[25] A. S. Putra and O. M. Febriani, “Knowledge Management Online
Application in PDAM Lampung Province," in Prosiding International conference on Information Technology and Business (ICITB), 2018, pp. 181-187.

[26] A. S. Putra, O. M. Febriani, and B. Bachry, "Implementasi Genetic Fuzzy System Untuk Mengidentifikasi Hasil Curian Kendaraan Bermotor Di Polda Lampung," SIMADA (Jurnal Sist. Inf. dan Manaj. Basis Data), vol. 1, no. 1, pp. 21-30, 2018.

[27] A. S. Putra, H. Sukri, and K. Zuhri, "Sistem Monitoring Realtime Jaringan Irigasi Desa (JIDES) Dengan Konsep Jaringan Sensor Nirkabel," IJEIS (Indonesian J. Electron. Instrum. Syst., vol. 8, no. 2, pp. 221-232.

[28] D. P. Sari, O. M. Febriani, and A. S. Putra, "Perancangan Sistem Informasi SDM Berprestasi pada SD Global Surya," in Prosiding Seminar Nasional Darmajaya, 2018, vol. 1, no. 1, pp. 289-294. 